\title{
A Study of the Mediating Role of Product Management on Relationship between Market orientation and firm Performance (Case Study: Home appliances manufacturing companies in Esfahan Province)
}

\author{
Ph.D. Hassan Ghorbani \\ Assistant Professor, Management Department, Islamic Azad University, Branch of Mobarake, \\ Iran \\ Email: ghorbani2007ha@yahoo.com
}

\begin{abstract}
Azade Yaghootkar ${ }^{1}$
M.S.C., Business management, Islamic Azad University, Branch of Mobarakeh, Iran Email: Bazargan_2013@yahoo.com
\end{abstract}

DOI: 10.6007/IJARBSS/v3-i11/338 URL: http://dx.doi.org/10.6007/IJARBSS/v3-i11/338

\begin{abstract}
The present paper, titled 'A Study of the Effect of market orientation on SME firm performance the mediating role of product management' Seek to answer the question Which aspects of product management how affect the firm performance Thus the product management literature, as well as market orieantation and performance in home appliances factories in Isfahan Province are examined. This research, in terms of its purpose, is an applied one; and in terms of implementation method, is a survey with a correlation approach. The statistical population include 84 managers (senior, marketing, manufacturing and R\&D) of the home appliances manufacturing companies in Esfahan Province. The data collection tool is a researcher-made questionnaire containing 30 items, of which the validity has been confirmed using the comments from advisors, professionals and experts; and the reliability, determined through Cronbach's alpha coefficient of 90\%) The questionnaire includes personal data and main, specialized items for examining the research hypotheses. The collected data were analyzed using SPSS and AMOS software programs through statistical tests at descriptive (frequency, percentage, accumulated percentage, average and standard deviation) and inferential (regression modeling, variance analysis, non- parametric Kolmogorov and Smirnov test, and Freedman non-parametric test) levels. According to the results obtained, all hypotheses were supported. Therefore, it was concluded that the product management as a mediator has a significant effect on the relationship between market orientation and performance.
\end{abstract}

1. Corresponding Author: M.S.C., Business management, Islamic Azad University, Branch of Mobarakeh, Iran

Bazargan_2013@yahoo.com 
Key words: Market Orientation, Channel analysis and support, Positioning, Integration, Performance, Product Management

\section{Introduction}

The product management as a concept has a powerful relationship with companies' marketing function. It has been attended by Procter and Gamble as one of the successful companies in terms of product management system implementation in 1690s. Also many of the successful companies change their product management system during past years (Wood and tendon, 1994). This system, which concentrates on the product as a focus point of management structure, delegates the responsibility of product developing, creating, and marketing to the product manager. Based on this system, the company concentrates on the responsibility of integrating all of the necessary functions of product management or product line (Karlsson and Olsson, 1998). Although this system has not been used by medium and big companies comprehensively, but it seems that they used direct and indirect strategies of product management that derives from their simple and flexible organizational structure (Becherer et al., 2003). In traditional method, the responsibilities of product management are delegated to the intra-organizational informal systems. Although there are many behaviors of classic product management in the organizations in today's world, but it is should be remembered that product management, as a research area, has been ignored. With respect to the important excepts, many of the journals are grouped based on the factors (E.G. Gorchels, 2005).

The market-orientation has been attended in the academic studies and researches as an effective strategy in the companies' strategy from 1980s. Market-orientation is an ancient concept in the marketing theory and desire to the concept of learning about market. In other words, it is concentrated on development of market perception and the use of it in the marketing activities. This is why that market-orientation can be defined as the commercial philosophy that directs the companies' competitive strategies. In other words, marketorientation in a business is a degree in which the company collects information from customers and uses it in developing a strategy to satisfy the customers' needs and then use it in order to satisfy the customers' needs and wants. Generally, it can be said that market-orientation concentrates on this fact that the products should reflect the market demand and consumers' preferences (Mahan, Comprehensive management information).

Product management unlike to market-orientation concept determines the company's behavior beyond the traditional functions and thinks about how the organization can achieve and process the external information. On the other hand, market-orientation is not a complex set of internal and external interactions that the company has to use them in order to achieve optimum performance. Therefore, product management can be considered as organizational behaviors that reinforce the relationship between market-orientation and company performance (Hansen and Eggers, 2010). The purpose of this study is to examine the mediating role of product management in the relationship between market-orientation and business performance. The literature review, research methodology, data analysis, conclusion, limitations, and suggestions are the main topics that will be covered in the future sections. 


\section{Literature review}

\section{2-1. Market-orientation}

Market-orientation is a concept that derives from marketing concept (Felton, 2006). He believes that the concept of market-orientation is a common mental status that is combined for achieving organizational goal in the long-term period based on the integration and coordination of companies' activities. McNamara (2000) adopts a more comprehensive approach and refers to market-orientation concept as a commercial management approach that is focused on the customer-orientation and benefits and recognizing the important role of marketing in contacting market needs. According to Kotler, there are three main issues that concentrate on the especial definition of market-orientation, coordinated marketing, and profiting. The approach of Kohli and Jaworski (1993) is the main approach in market-orientation that has been presented in the following section.

They refer to market-orientation as formation of comprehensive market information in terms of customers' needs, distributing information in the internal environment of organization, and responding the customers' needs and wants. Their definition reflects the approach of Barks Diel and Darden. The reason is that their definition concentrates on the especial activities not philosophical perceptions and thereby facilities the operationalization of marketing concept. Also Kohli and Jaworski (1993) describe that the structure of market-orientation consist of three sections. These include information creation, information distribution, and responding. Narver and Slater (1990) refer to market-orientation as the organizational culture that creates the most effective and efficient behaviors for providing better value to the buyers and thereby obtaining the best performance in business and trade. Narver and Slater (1990) conclude that market-orientation consists of three behavioral factors including customer-orientation, competitor-orientation, and intersectional coordination.

\section{2-2. Product management}

One of the main interests of marketing managers and producers is transmitting the products to the targeted market. Distribution should be done so exactly that supply the products in time that it is needed in market. Also it should have adaptability with marketing mix including product, price, place, and promotion (Maleki et al., 2011). On the other hand, the managers and companies' interest in today's competitive market is that help the customers in defining position of product and direct them toward the best position through developing intellectual strategies and policies. The products position is the product's situation in the customers' mind. The customers will not desire to buy a product if they feel that the product is similar to other products and has not any additional benefits (Kotler et al., 2006). The results of the studies revealed that the appropriate perception of dimensions and measures that customers use them in valuate competitors' marketing plan and then decide to buy is the key factor in determining product position (Saeidnia and Firozian, 2006).

Also the results of different studies revealed that responding the customers' needs and wants requires actual cooperation of organizational departments. Many managers believe that the market information should be distributed across the organization in order to adapt with market needs. This is the marketing department function to distribute the market information among different organizational departments. The effective distribution of information is a very important function. The reason is that it provides a common basis for coordinating all of the 
units' activities. Norinia (2007) refers that integration is the process of combining the interrelated components that create integration with each other (Lamei, 2007). All of the employees in every organizational level share the competitors' information in a market-orientation business.

\section{2-3. Market orientation and product management}

The beginning point of market-orientation is collecting market data. Although the market information is the information of customers' needs and preferences, but it is should be remembered that it also refers to examining the effects of external factors such as governmental rules on these needs. Also the information of environmental exploring is another part of the market information (Norinia, 2007). Predicting customers' needs is a critical function. The reason is that development of a new product needs many times. This refers to the important role of market-orientation in analyzing and supporting channels in order to recognize the customers' needs and environmental changes (Rezaei Dolatabadi, 2005).

Positioning products based on the customers' needs and wants is created in targeted market. Product positioning is necessary and important for both existing products and new ones. The reason of such importance is that the customers' needs and wants and marketing environment are changing continuously. Some marketing managers use new positioning for changing consumers' attitudes toward products (Roosta et al., 2009). All of the studies that have been done in terms of market-orientation revealed that there is a powerful relationship between market-orientation, profitability, customer maintenance, increase in sell, and success of new products.

The performance of product management organization can be directed through structural limitations and obstacles in the organization, quality of marketing processes, roles and responsibilities, knowledge, and competencies. Also they remember that integration paves the ground for functions expertise between organizational departments in responding the market needs rapidly. This refers to the relationship between market-orientation and integration of units (Tyagi and Sawhney, 2010). With regard to the literature review, the following hypotheses can be developed.

1. Market orientation influences the channel analysis and supporting in Isfahan Appliances Companies significantly.

2. Market orientation influences success of the products in Isfahan Appliances Companies significantly.

3. Market orientation influences integration of the marketing and technical units in Isfahan Appliances Companies significantly.

\section{2-4. Product management and performance}

The channel analysis and supporting is one of the main dimensions in the product management that measures the company's capabilities in terms of formal and informal systems that monitor the product through quantitative and qualitative feedbacks. Such a feedback can be used by company to analyze the data and make decisions about product category, pricing, supporting, and sale prediction. The results of several studies in terms of product management revealed that product management as a mediating variable influences the relationship between market- 
orientation and performance. The results of this study indicated that the channel analysis and supporting and technical units are effective on the performance. Product positioning is another dimension of product management that includes several activities such as desire to offering better products, giving feedback from customers through primary researches, and managing market tests. On the other hand, external environment influences the purposes of products design and can measure the company's ability to maintain and reinforce the product position. The direct effect on the performance has been examined in this dimension. Final aspect of product management in this study is marketing integration and technical section that reflects the companies' capabilities as an interaction between marketing and technical section. When the market-orientation culture is instituted in the organization, it will be expected that the company's ability for offering products continuously be promoted and this is a reciprocal functional ability results in improved performance (Roach, 2011).

With regard to the literature review that has been indicated in past section, the following hypotheses can be developed.

4. The channel analysis and supporting influences performance of Isfahan Appliance companies.

5. The product positioning influences performance of Isfahan Appliance companies.

6. The integration of marketing and technical unit influences performance of Isfahan Appliance companies.

\section{The conceptual model of study}

The conceptual model of study has been presented in figure 1. The relationships between variables of this model refer to the research hypotheses.

Fig 1: The conceptual model of study

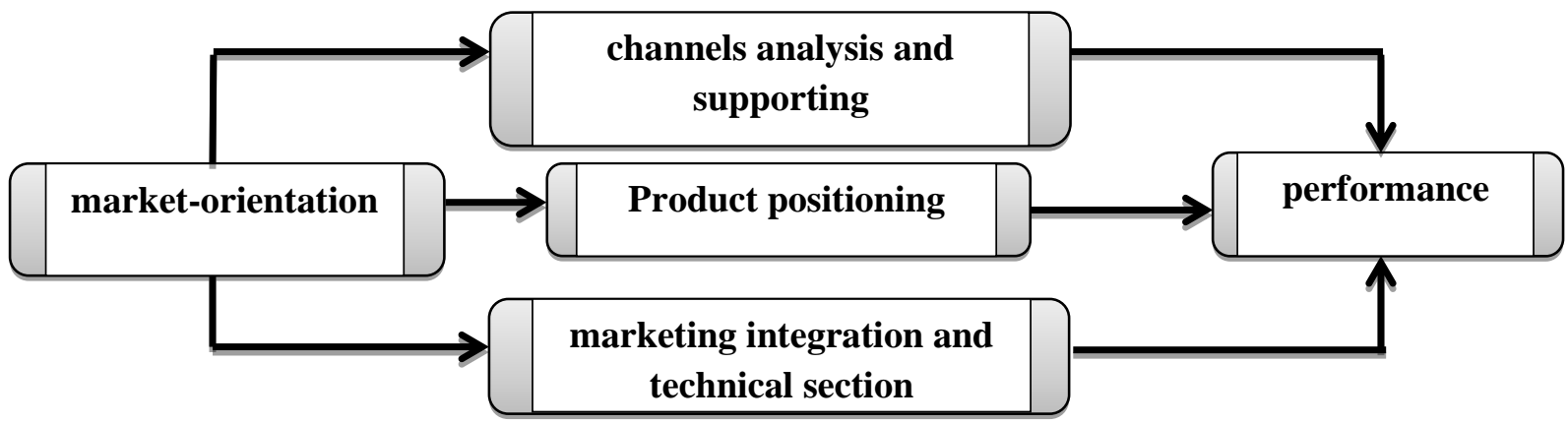

\section{Research methodology}

This study is a descriptive research from methodological view and is a practical one from purpose perspective. Also this study is a correlational research from identity view.

The relationship between research variables will be analyzed based on the research purposes in this study. Also the relationship and its type between independent and dependent variables will be examined in this study. In order to collect the research data, library and field study methods have been followed. This is why that it can be said that this study is a field study based on 
identity and research methodology. Finally, it should be said that this study is a descriptivesurvey study.

\section{Statistical population and sample}

The statistical population of this study includes production managers, marketing managers, senior managers, and research and development managers of Isfahan Appliance companies. This population consists of 84 persons. Because this population was as small as that it is not necessary to sampling.

\section{Data-collection method}

In order to collect the research data, a self-administrated questionnaire with 47 items has been used. This includes three parts. A summary of research purpose and its questions have been indicated in the first part of questionnaire. The second part of this questionnaire refers to the demographic characteristics including age, educational levels, gender, job experience, and job position. The third part refers to 42 questions for examining the relationship between marketorientation and product management (channel analysis and supporting, positioning, marketing integration, and technical unit). The third part of the questionnaire has been developed in fivepoint Likert scale. In order to collect the research data, 84 questionnaires have been distributed among statistical population members that 76 members indicated the questionnaire completely. Unfortunately, 6 questionnaires were unusable in final analysis because of its defections. Finally, 70 questionnaires were used in final analysis.

\section{Reliability and validity of the questionnaire}

Although the questionnaire has been standardized by its developer, but it is better to examine its reliability and validity. This is why that reliability and validity of this questionnaire has been examined and its results have been indicated in the following section.

\section{7-1. Validity of the questionnaire}

Validity refers to this fact the data-collection instrument can measure the research variables. The importance of validity is that the insufficient and inappropriate instrument can make the research and its finding unusable and invalid. Validity of every data-collection instrument can be measured and determined by any expert in that field. In order to this, the academic experts and professors were asked to review the questionnaire and indicate their modifications and corrections.

\section{7-2. Reliability of the questionnaire}

When a data-collection instrument is reliable that there is a powerful correlation between scores and observation and actual scores. In order to examine reliability of this questionnaire, Cronbachs' Alpha Coefficient has been used in this study. In order to this, 30 questions of 30 primary questionnaires have been entreated to the SPSS and then its coefficient was calculated that is 0.90 .

Because the minimum coefficient of Cronbachs' Alpha should be 0.70 for accepting it and the coefficient of this questionnaire is 0.90 , it can be said that the questionnaire of this study is desirable one. Therefore, it can be concluded that the questionnaire of this study is a reliable data-collection instrument. Also Cronbachs' Alpha coefficient has been calculated for all of the research variables autonomously that its results have been indicated in table 1. 
Table 1: scale, frequency of the questions, and Cronbachs' Alpha coefficient of the questions

\begin{tabular}{|c|c|c|c|}
\hline Variables & $\begin{array}{l}\text { Scale type: Likert } \\
\text { five-point }\end{array}$ & $\begin{array}{l}\text { Number of } \\
\text { questions }\end{array}$ & $\begin{array}{l}\text { Cronbachs' } \\
\text { Alpha coefficient }\end{array}$ \\
\hline product positioning & & 29 & 0.86 \\
\hline channels analysis and supporting & & 5 & 0.83 \\
\hline product positioning & & 4 & 0.70 \\
\hline $\begin{array}{l}\text { marketing integration and technical } \\
\text { section }\end{array}$ & & 3 & 0.77 \\
\hline market-orientation & & 8 & 0.74 \\
\hline performance & & 5 & 0.77 \\
\hline Total & & 42 & 0.90 \\
\hline
\end{tabular}

\section{Data analysis}

\section{8-1. The respondents' demographic characteristics}

The respondents' demographic characteristics have been presented in table 2. As indicated in this table, $98.6 \%$ of the respondents were male and $1.4 \%$ of them were female. From age view, $40 \%$ of the respondents had 30-39 years old that indicate they are young respondents. About $50 \%$ of the respondents had academic educational levels (M.Sc.). Finally, the findings showed that $42 \%$ of the respondents had 6-10 years job experiences. 
Table 2: the respondents' demographic characteristics

\begin{tabular}{|c|c|c|c|c|c|}
\hline Variable & Levels & $\%$ & Variable & Levels & $\%$ \\
\hline \multirow{3}{*}{ Gender } & Male & 98.6 & \multirow{3}{*}{$\begin{array}{c}\text { Educational } \\
\text { levels }\end{array}$} & $\begin{array}{c}\text { Less than } \\
\text { M.Sc. }\end{array}$ & 22.9 \\
\hline & \multirow{2}{*}{ Female } & \multirow{2}{*}{1.4} & & M.Sc. & 44.3 \\
\hline & & & & M.A. & 32.9 \\
\hline \multirow{5}{*}{ Age } & $<30$ & 21.4 & \multirow{5}{*}{$\begin{array}{c}\text { Job } \\
\text { experiences }\end{array}$} & $<5$ & 15.7 \\
\hline & $30-39$ & 51.4 & & $6-10$ & 44.3 \\
\hline & $40-49$ & 12.9 & & $11-15$ & 11.4 \\
\hline & \multirow{2}{*}{$>50$} & \multirow[t]{2}{*}{14.3} & & $16-20$ & 4.3 \\
\hline & & & & $>20$ & 24.3 \\
\hline
\end{tabular}

\section{8-2. Measurement model}

Generally, two main models are tested in the structural equation models. The first is measurement model for latent variables. This model refers to the factor loadings of observed variables for latent variables. The goodness of fit measures has been indicated in the following table for all of the latent variables. As indicated in table 3, all of the goodness of fit indexes is in acceptable and in desirable range.

Table 3: the goodness of fit indexes for structural equation modeling

\begin{tabular}{|c|c|c|}
\hline The fit indices & indexes & Secondary model \\
\hline \multirow{4}{*}{ Absolute } & NPAR & 15 \\
\cline { 2 - 3 } & DF & 0 \\
\cline { 2 - 3 } & $\mathrm{P}>0.05$ & --- \\
\hline \multirow{4}{*}{$\begin{array}{c}\text { Comparative or } \\
\text { relative }\end{array}$} & Square) & 0 \\
\cline { 2 - 3 } & $\mathrm{AGFI}>0.9$ & --- \\
\cline { 2 - 3 } & $\mathrm{GFI}>0.9$ & 1 \\
\cline { 2 - 3 } & $\mathrm{TLI}>0.9$ & --- \\
\hline \multirow{3}{*}{ Thrifty } & $\mathrm{NFI}>0.9$ & 1 \\
\cline { 2 - 3 } & $\mathrm{CFI}>0.9$ & 1 \\
\cline { 2 - 3 } & $\mathrm{PNFI}>0.5$ & 0 \\
\cline { 2 - 3 } & $\mathrm{PCFI}>0.5$ & 0.667 \\
\cline { 2 - 3 } & $\mathrm{RMSEA}<0.08$ & --- \\
\hline
\end{tabular}




\section{8-3. Structural model}

It is necessary to examine the structural model and the relationship between latent variables after testing the measurement models. It is possible to test the research hypotheses through structural model. The conceptual model of this study has been indicated in figure 2. In order to test the research model and test the research hypotheses, Amos Graphics has been used. In order to use Amos, it is should be remembered that $\gamma$ refers to the effects of external variables on the internal variables and the $\beta$ refers to the effects of internal variables on each other. In order to examine significance of $\beta$ and $\psi$, it is necessary to examine t-value of every path. The coefficients of path have been indicated in figure 2 .

Fig 2: the model of study (path analysis model)

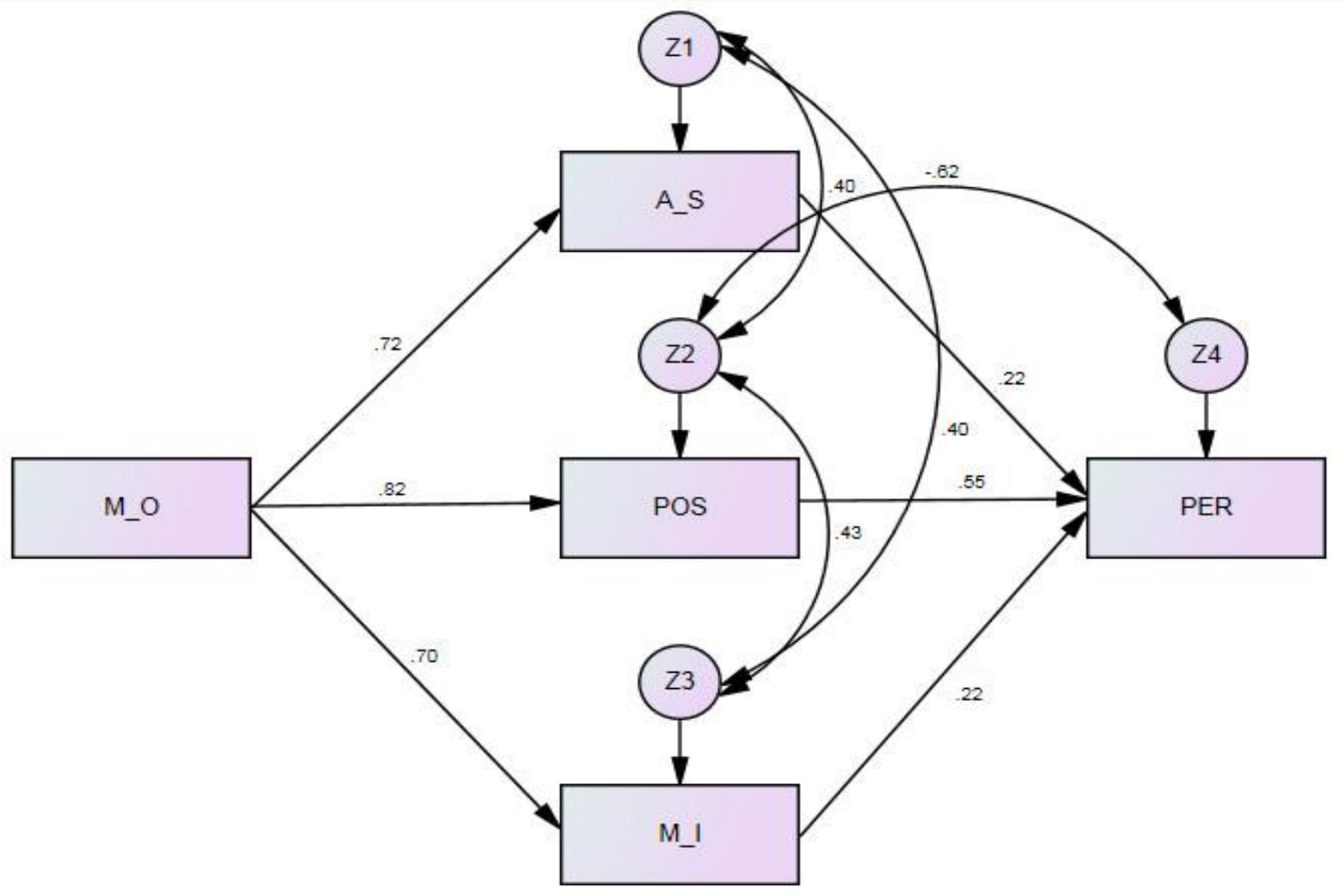

\section{8-4. The findings}

It is necessary to present average, standard deviation, and variance of the research variables before examining the research hypotheses. These findings have been indicated in table 4 . The most score was for marketing integration and the least score was for technical unit among research variables. 
Table 4: Descriptive statistics of the research variables

\begin{tabular}{|c|c|c|c|c|}
\hline Variable & No. Question & Average & $\begin{array}{c}\text { Standard } \\
\text { deviation }\end{array}$ & Variance \\
\hline $\begin{array}{c}\text { product } \\
\text { management }\end{array}$ & $1-29$ & 2.843 & 0.683 & 0.466 \\
\hline $\begin{array}{c}\text { channels analysis } \\
\text { and supporting }\end{array}$ & $1,3,5,6,17$ & 3.069 & 0.774 & 0.599 \\
\hline $\begin{array}{c}\text { product positioning } \\
\text { marketing } \\
\text { integration and } \\
\text { technical section }\end{array}$ & $8,15,18,22$ & 2.939 & 0.796 & 0.508 \\
\hline market-orientation & $30-37$ & 2.779 & 0.817 & 0.668 \\
\hline Performance & $38-42$ & 3.917 & 0.820 & 0.673 \\
\hline
\end{tabular}

Also significance of the relationships between components of secondary model and coefficients of determination has been indicated in table 5 .

Table 5: Test the hypothesis

\begin{tabular}{|l|c|c|c|c|c|c|}
\hline & $\begin{array}{c}\text { Secondary } \\
\text { hypotheses }\end{array}$ & $\begin{array}{c}\text { Standard } \\
\text { coefficient }\end{array}$ & $\begin{array}{c}\text { Standard } \\
\text { error } \\
\text { S.E. }\end{array}$ & $\begin{array}{c}\text { Critical } \\
\text { ratio C.R. }\end{array}$ & p-value & Result \\
\hline $\begin{array}{l}\text { market-orientation --- } \\
\text { > channels analysis } \\
\text { and supporting }\end{array}$ & $\mathrm{H} 1$ & 0.721 & 0.079 & 8.648 & $* * *$ & $\begin{array}{c}\text { Is } \\
\text { confirmed }\end{array}$ \\
\hline $\begin{array}{l}\text { market-orientation --- } \\
>\text { product positioning }\end{array}$ & $\mathrm{H} 2$ & 0.815 & 0.068 & 11.701 & $* * *$ & $\begin{array}{c}\text { Is } \\
\text { confirmed }\end{array}$ \\
\hline $\begin{array}{l}\text { market-orientation --- } \\
>\text { marketing } \\
\text { integration and } \\
\text { technical section }\end{array}$ & $\mathrm{H} 3$ & 0.698 & 0.075 & 8.087 & $* * *$ & Is \\
\hline $\begin{array}{l}\text { channels analysis and } \\
\text { supporting ---> } \\
\text { performance }\end{array}$ & $\mathrm{H} 4$ & 0.219 & 0.102 & 2.170 & 0.030 & Is \\
\hline $\begin{array}{l}\text { product positioning --- } \\
>\text { performance }\end{array}$ & $\mathrm{H} 5$ & 0.548 & 0.106 & 5.057 & $* * *$ & Is \\
\hline
\end{tabular}




\begin{tabular}{|l|c|c|c|c|c|c|}
\hline & & & & & confirmed \\
\hline $\begin{array}{l}\text { marketing integration } \\
\text { and technical section - } \\
-->\text { performance }\end{array}$ & $\mathrm{H} 6$ & 0.221 & 0.111 & 2.189 & 0.029 & $\begin{array}{c}\text { Is } \\
\text { confirmed }\end{array}$ \\
\hline$* * *$ Proves that P is less than 0.001 & & & & & & \\
\hline
\end{tabular}

Based on the results of this study that have been indicated in tables and figures, it can be said that all of the research hypotheses are supported and all of the path coefficients are significant. It is necessary to examine the total, direct, and indirect effects in order to examine direct and indirect effects of dependent and independent variables. These results have been indicated in table 6.

Table 6: total, direct, and indirect effects

\begin{tabular}{|c|c|c|c|c|}
\hline $\begin{array}{l}\text { Dependent } \\
\text { variable }\end{array}$ & Independent variable & $\begin{array}{l}\text { Direct } \\
\text { effect }\end{array}$ & $\begin{array}{l}\text { Indirect } \\
\text { effect }\end{array}$ & $\begin{array}{l}\text { Total } \\
\text { effect }\end{array}$ \\
\hline $\begin{array}{c}\text { channels } \\
\text { analysis and } \\
\text { supporting }\end{array}$ & \multirow{3}{*}{ market-orientation } & 0.72 & 0 & 0.72 \\
\hline $\begin{array}{c}\text { product } \\
\text { positioning }\end{array}$ & & 0.82 & 0 & 0.82 \\
\hline $\begin{array}{c}\text { marketing } \\
\text { integration } \\
\text { and technical } \\
\text { section }\end{array}$ & & 0.70 & 0 & 0.70 \\
\hline \multirow{3}{*}{ performance } & $\begin{array}{c}\text { channels analysis and } \\
\text { supporting }\end{array}$ & 0.22 & $0.72 * 0.22$ & 0.16 \\
\hline & product positioning & 0.55 & $0.82 * 0.22$ & 0.45 \\
\hline & $\begin{array}{l}\text { marketing integration and } \\
\text { technical section }\end{array}$ & 0.22 & $0.70 * 0.22$ & 0.15 \\
\hline
\end{tabular}

\section{Conclusion}

The results of this study indicated that market-orientation influences the channel analysis and supporting ( $\gamma$ : 0.72). The result of this hypothesis is consistent with findings of Roach (2011). He indicated that there is a significant positive relationship between market-orientation and channels analysis and supporting. Also another part of the results of this study revealed that market-orientation influences product positioning positively $(\gamma: 0.82)$. The result of this hypothesis is supported by Karlsson and Olsson (1998). They found that the product management system concentrates on the product as a focus point of management structure and also delegates all of the responsibilities of creating, developing, and marketing products to 
the product manager. Based on this system, the company concentrates on integrating all functions of product management or product line. This refers to the positive effects of marketorientation on the product positioning. Also the results of this study revealed that marketorientation influences marketing integration and technical unit significantly ( $\gamma$ : 0.70). Tyagi and Sawhney (2010) found a significant positive relationship between market-orientation with marketing integration and technical section. In other words, the results revealed that the performance of product management organization can be directed through structural limitations in organization, quality of marketing processes, roles and responsibilities, knowledge and competency. Also they pointed out that integration paves the grounds for allocating function between departments for answering the customers' needs and wants based on the market needs. Another part of the results revealed that channel analysis and supporting influences performance positively ( $\gamma: 0.22)$. The result of this hypothesis is supported by Roach (2011). He pointed out that the product management has a mediating effect on the relationship between market-orientation and performance. The results of this study also revealed that product positioning influences performance significantly $(\gamma: 0.55)$. This result is supported by Milz and Darch (2008). They indicated that product positioning, channel analysis and supporting, and hyper-functional coordination influence business performance significantly. The results showed that marketing integration and technical section influence performance positively ( $\gamma: 0.22)$. This result in supported by Becherer et al. (2003) and Keskin (2006) findings. They found that the relationship and integration between organizational departments has a significant positive effect on the rapid adaptation in changes of market needs that can be used for improving organizational performance.

\section{Limitations of study and suggestion for future studies}

Every author has several limitations in his/her study that some of them exists in beginning of study. Also every comprehensive study has several limitations and difficulties that these prevent from generalizing its results to other cases. Recognizing these limitations paves the grounds for interpreting its results and promoting quality level of the future studies. There are several limitations in this study that some of these have been presented in the following sections. The difficulties that the managers facing in communicating managers, managers' sensitivity toward questionnaire, and inappropriate organizational culture are the main limitations of this study. Undoubtedly, the main limitation of every study is that the authors cannot generalize the results of the study to other cases. Such a limitation exists in this study and the authors cannot generalize its results and findings to other cases. Also this study has been done in an especial area of Iran in the city of Isfahan and thereby its results cannot be generalized to other cities of Iran.

The present study examine the market-orientation, product management (channel analysis and supporting, product positioning, marketing integration, and technical section), and performance. It is suggested that the future studies examine other variables such as customerorientation, competitors-orientation, and inter-functional coordination as product management components and then their effects are studied on the relationship between market-orientation and performance. It is suggested that the coordination of production is done before than production stage. Also it is necessary the new supporting services (such as education, technical supporting, confirmation, and introduction) are provided for sale forces. It 
is suggested that the sale data is analyzed and evaluated based on the predictions and marketing plans. The prediction and supervision on the sale and services departments should be systemic. Also it is necessary that market simulation methods are used in examining the product acceptance and new service acceptance. Also it is necessary that the products designs are supported through business analysis. The technical employees should be involved in goods and services marketing so much that can achieve sufficient awareness and knowledge. It is necessary that the technical and marketing employees have equal responsibility in the new product development. The organization should be organized so exactly that explores the industry in terms of new ideas, trends, and desires for improving products introduction. The organization has to pave the grounds for examining the effectiveness of promotional activities and encourage the employees to create new ideas. It is necessary that quality of products and services is evaluated by final customers. Also the managers have to evaluate the customer services daily so exactly that it is possible to eliminate the weaknesses and improve the strengths. The results of customer satisfaction should be distributed continuously across the organization so exactly that the employees achieve more information about customer needs for obtaining higher levels of performance and also achieving more motivation for participating. Also it is necessary that market information is provided for employees in order to make sound decisions in terms of goods and services. It is suggested that the future studies examine the market-orientation and product management capabilities. Also it is necessary that the future authors examine the mediating role of innovation in the relationship between performance and other aspects such as market-orientation and entrepreneurship aspects. It is suggested that continuous efforts are done to study the entrepreneurship literature. Also it is suggested that other effective factors on the performance be measured so that paves the grounds for managers' success. Finally, it is suggested that this study be done in other industries so that it is possible to compare their results with each other.

\section{References}

Rezaei Dolatabadi H., Khaef Elahi A., 2005. A model to determine the impact of market orientation on business performance and marketing capabilities in the industry. Journal of Agricultural Science ,No. 1, pp. 161-131.

Roosta A., Venus, Ebrahimi D., Abdulhamid. , 2009. Marketing Management. Thirteenth Edition. Tehran: Institute for Humanities reading and writing books. The publisher. 475 pages.

Saeidnia H., Firozian M., 2006. Positioning a product in the home appliance industry in Greater Tehran techniques using Perceptual Map. Journal of Marketing Management. pp. 84-65.

Kotler F., Gray, Armstrong. , 2006. Translated by B. lustrous. Principles of Marketing. Ninth printing. Learned Publishing. 932 pages.

Lamei A., 2007. The concept of integration. Journal of Medicine and purification ,No. 67-66, pp. 30-22.

Comprehensive management information. Dimensions of Market-oriented strategy. Mahan. All the the text. (http://mahanco.com/component/content/article/39)

Maleki M., Norouzzadeh Sani A., Alyshah M, Nemati R., 2011. Distribution channels and types of industrial and consumer products. All the the text.

Norinia R. , 2007. Market orientation Marketing hearts. Compass Magazine, 181: 36-32. 
Becherer, R.C., Halstead, D. and Haynes, P.J. (2003). "Marketing orientation in SMEs: effects of the internet environment" . New England Journal of Entrepreneurship, Vol. 6 No. 1, pp. 13-22.

David C. Roach, (2011). "The impact of product management on SME firm performance", Journal of Research in Marketing and Entrepreneurship, Vol. 13 Iss: 1 pp. 85-104.

Felton, A.P. (2006). "Making the marketing concept work", Harvard Business Review, JulyAugust, pp. 55-65.

Gorchels, L. (2005). The Product Manager's Handbook, McGraw-Hill, New York, NY.

Hansen, D.J. and Eggers, F. (2010). "The marketing/entrepreneurship interface; a report on the 'Charleston Summit' ", Journal of Resaerch in Marketing and Intepreneurship, Vol. 12 . No.1, pp. 42-53.

Karlsson, C. and Olsson, O. (1998). "Product innovation in small and larg enterprises", Small Business Economics, Vol. 10 No. 1, pp. 31-46.

Keskin, H. (2006). "Market orientation, learning orientation, and innovation capabilities in SMEs", European Journal of Innovation anagement, Vol. 9 No. 4, pp. 396-417.

Kohli, A.K.\& Jaworski, B.J. (1993). "Market orientation: antecedents and consequences", Journal of Marketing, Vol. 57 .No. 3, July, pp. 53-70.

McNamara, C.P. (2000). "The present status of the marketing concept". Journal of Marketing, Vol.36, pp. 50-57.

Miles, M. and Darroch, J. (2008). "A commentary on current research at the marketing and entrepreneurship interface of Small Business Management", Vol. 46 No. 1, pp. 46-9.

Narver, C. \& Slater, F. (1990). "Does competitive environment moderate The market orientation performance relationship?". Journal of Marketing .Vol.58, No8, pp.46-55.

Nraver,J.C., \& Slater,S.F. (1990). "The effect of a market orientation on business profitability". Journal of Marketing, 54(4), pp. 20-35.

Tyagi, R.K. and Sawhney, S.S. (2010). "High-performance product management: the impact of structure, process, competencies, and role definition", The Journal of Product Innovation Managment, Vol. 27 No. 1, pp. 83-96.

Wood, V. and Tandon, S. (1994). "Key components in product management success (and failure)", The Journal of product Brand Managment, Vol. 3 No. 1, pp. 19-38. 